\title{
Numerical simulation of dual-phase steel based on real and virtual three-dimensional microstructures
}

Received: 17 July 2020 / Accepted: 27 January 2021 / Published online: 18 February 2021

(C) The Author(s) 2021

\begin{abstract}
Dual-phase steel shows a strong connection between its microstructure and its mechanical properties. This structure-property correlation is caused by the composition of the microstructure of a soft ferritic matrix with embedded hard martensite areas, leading to a simultaneous increase in strength and ductility. As a result, dual-phase steels are widely used especially for strength-relevant and energy-absorbing sheet metal structures. However, their use as heavy plate steel is also desirable. Therefore, a better understanding of the structure-property correlation is of great interest. Microstructure-based simulation is essential for a realistic simulation of the mechanical properties of dual-phase steel. This paper describes the entire process route of such a simulation, from the extraction of the microstructure by 3D tomography and the determination of the properties of the individual phases by nanoindentation, to the implementation of a simulation model and its validation by experiments. In addition to simulations based on real microstructures, simulations based on virtual microstructures are also of great importance. Thus, a model for the generation of virtual microstructures is presented, allowing for the same statistical properties as real microstructures. With the help of these structures and the aforementioned simulation model, it is then possible to predict the mechanical properties of a dualphase steel, whose three-dimensional (3D) microstructure is not yet known with high accuracy. This will enable future investigations of new dual-phase steel microstructures within a virtual laboratory even before their production.
\end{abstract}

Keywords Dual-phase steel $\cdot$ Microstructure-based simulation $\cdot 3 \mathrm{D}$ tomography $\cdot$ Microstructure generation . Finite element method · Deal.II · Dream.3D

\section{Introduction}

Steel is the most important construction material of modern times, with a production quantity exceeding that of all other metals by more than a factor of 10 [1]. Due to the large variety of possible microstructural states and alloy constituents, various classes of steels have been developed over time. One of these classes is dualphase steel. It consists of a soft ferritic matrix in which hard martensite regions are embedded. As a result

Communicated by Andreas Öchsner.

F. Scherff · S. Diebels $(\varangle)$

Lehrstuhl für Technische Mechanik, Universität des Saarlandes, Saarbrücken, Germany

E-mail: s.diebels@mx.uni-saarland.de

J. Gola · D. Britz · F. Mücklich

Lehrstuhl für Funktionswerkstoffe,

Universität des Saarlandes, Saarbrücken, Germany

F. Scherff $\cdot$ J. Gola $\cdot$ S. Scholl $\cdot$ K. Srivastava $\cdot$ T. Staudt

AG der Dillinger Hüttenwerke, Dillingen, Germany 
of this microstructure, dual-phase steels are characterized by high ductility combined with high strength [2]. Dual-phase steel is mainly used as thin sheets for strength-relevant and energy-absorbing components in the automotive and aerospace industries [3,4]. However, the special properties make it desirable to use dual-phase steels also in heavy plates, for example in pipeline construction [5-7]. A wide variety of simulation methods are used to further optimize these properties. Classical continuum mechanical models describe the material as a homogeneous single-phase continuum and try to reproduce the properties of the dual-phase steel only with the help of complex material models [8,9]. However, due to its pronounced structure-property correlation [2], this approach has significant disadvantages. As for many materials, the properties of a dual-phase steel are decisively determined by its microstructure, especially by the quantity, shape and distribution of martensite areas in a ferrite matrix [2,10-13]. Models that consider steel as a single-phase continuum are exactly fixed to one steel, which means that even minor structural changes require a readjustment of the model. In part, the influence of the microstructure is taken into account by extending the material models, as available information on the internal structure of the steel influences the parameters of the material model $[14,15]$. However, the interaction of ferrite and martensite in the microstructure of dual-phase steel can only be fully described if both phases and their distribution are directly included in the analysis. This is implemented by microstructurebased simulations within the framework of the finite element method (FEM, [16]). They offer the possibility to include the exact effects of the microstructural composition of the steel into consideration by modelling the two phases of the steel as discrete areas of the FE mesh.

In order to enable any kind of microstructure-based simulations, the underlying structure must first be obtained by means of imaging methods. For structural analysis, new methods of 3D analysis have to be developed in order to precisely describe the microstructure. According to Hadwiger et al. only four parameters are enough to describe the geometry of a two-phase structure [17]. However, only three of them can be determined from 2D micrographs using the methods of stereological estimates. Stereology therefore does not provide exact information on important parameters such as the number of particles per volume, connectivity, size distributions and particle shape. Even basic parameters such as the number of particles, their average size and size distribution can only be determined approximately, while heterogeneous structures cannot be described at all [18]. Therefore, 3D microstructure analysis of a representative volume is important to calculate these parameters accurately. This process is complex and time-consuming, especially in the 3D case [3, 19]. Frequently used procedures are X-ray micro-computed tomography $(\mu \mathrm{CT})$ [20-22] and serial sectioning tomography [23-28]. In the $\mu \mathrm{CT}$, a sample is irradiated with X-rays from many different directions. A 3D image of the internal structure of the sample is then calculated by filtered rear projection of the recorded absorption profiles [29]. Serial sectioning tomography is based on the serial production of a large number of two-dimensional (2D) images of the sample. A thin layer of the sample is removed between the individual images, and the 2D images are digitally combined to form the 3D structure of the examined sample volume. A section preparation by mechanical polishing with image recording in the light optical microscope characterizes the serial light optical sectioning tomography [23,24,27]. A serial sectioning tomography based on a section preparation by a focused ion beam (FIB) with image acquisition in a scanning electron microscope (SEM) is called FIB/SEM serial sectioning tomography $[25,26,28]$. The methods mentioned are all suitable for the preparation of a microstructure tomography on metallic samples, but not all methods can be applied to steel. Low carbon steel, as used in this work, presents some challenges in terms of contrast, since the individual structural components usually differ only minimally in their chemical composition [30,31]. In general, contrasting the steel phases is a challenge. Thus, an etching step must be integrated into almost every tomography method [24]. Other restrictions include diamond cutting, as they form carbides on the steel when sufficient forces are applied [23]. SEM methods are problematic because of the contrast. In FIB/SEM tomographies there is a high time expenditure and the etching image contrast needed for a classification is not visible. Additionally, the required microstructure volume exceeds the maximum sample volume of common FIB/SEM devices [3,32]. Nevertheless, by adding a laser [33] or using other ion sources such as xenon [34] (instead of gallium), the tomographed volume can be increased. In addition to the classical SEM images also other signals (e.g. energydispersive X-ray spectroscopy or electron backscatter diffraction) can be used for tomographies [3]. $\mu \mathrm{CT}$ devices are not suitable in the case of the steels under consideration. Due to the small difference in carbon content the different phases of the steel do not show sufficient contrast under X-rays in the $\mu \mathrm{CT}$ according to Lambert-Beer. For these reasons, light optical serial sectioning tomographies are still one of the widely used methods to produce a large-scale steel tomography.

The complexity of the geometry under consideration and the large size of the volume to be investigated are common problems in simulations based on real microstructures [3,35]. Tomographies in the size range of the representative volume element (RVE) of dual-phase steel often consist of several million to several hundred 
million voxels. In this context, the RVE describes the section of the microstructure that is just large enough to contain all relevant information about the microstructure [36-38]. Although the size of the FE mesh can still be reduced by sophisticated, unstructured geometry conforming meshing, the possible data reduction is limited due to the complexity of the structures. Many works therefore consider only 2D microstructures [38-41]. In addition to the reduced numerical effort of the 2D calculation, the experimental effort also decreases in 2D, since only a single SEM image or micrograph is sufficient to determine the microstructure. However, the real material behaviour is not fully mapped in simulations when 2D microstructures are used, see [19,41-43]. The main reason for this is the lack of information about the mechanically relevant material areas in the direct vicinity above or below the selected $2 \mathrm{D}$ section and about the 3D connectivity.

As another approach, simulations based on virtual microstructures were carried out already very early in order to avoid the experimental and numerical difficulties of real microstructures described above. The work of Karlsson et al. [44-46] is to be especially emphasized here. The aim is to generate smaller, more easily meshable microstructures and to dispense with the complex, experimental determination of the real microstructure. There are many different ways to create virtual microstructures, e. g. tessellations [47-52] or physically motivated simulations of structural development [53-55]. In the presented work, geometric entities are used in the sense of a statistically similar RVE [3,56-58]. For a detailed overview of various other methods for generating virtual microstructures, also for other material classes, a comprehensive review article by Bargmann et al. [59] is referred to. Despite all the advantages of virtual structures, simulations based on real microstructures are still an indispensable reference for the simulation based on virtual microstructures. In addition to the generation of smaller and less computationally intensive RVEs, a major advantage of virtual microstructures is that they can be used for the prospective investigation of the properties of new microstructures. For that reason, the virtual microstructure is not fitted to the real microstructure's geometry but to a set of new geometric parameters.

In this work, the entire process chain of the numerical investigation of dual-phase steel is presented, from the experimental determination of the microstructure properties to the implementation of the numerical models in the open source $\mathrm{C}++$ program library deal.II $[60,61]$ and the simulation of the mechanical properties on the basis of the 3D microstructure. As one of the most important experiments for the characterization of materials, the uniaxial tensile test serves as a reference in the simulation. As sample necking and damage are not taken into account, only the deformation range below $10 \%$ strain is observed. In addition to the simulation based on the real microstructure of the steel, a process for the generation of virtual microstructures is also developed, enabling both the creation of virtual microstructures for known real structures and the evaluation of new microstructures before they are produced. The paper is organized as follows: in Sect. 2 the investigated material as well as the experimental methods for the determination of the real microstructure and the single-phase properties are presented. Sect. 3 covers the numerical methods, i.e.the FE implementation of the mechanical simulation and the structure generation process. In Sects. 4 and 5 the results for the simulations on real and virtual microstructures are shown and discussed. Section 6 concludes the work.

\section{Material and experimental methods}

\subsection{Investigated dual-phase steel}

For the simulation, four samples DP1 to DP4 from thermomechanically rolled steel plates with a carbon content of approximately $0.06 \%$ and a carbon equivalent of approximately $0.38 \%$ were used. The final twophase microstructures consisting of a ferritic matrix and a martensitic second phase, with second phase fractions from $9.24 \%$ for DP1 to $16.46 \%$ for DP4, were obtained by varying cooling conditions. In Fig. 1 light optical images are shown using 500x resolutions after 3\% Nital etching. Lower cooling temperature results in equiaxed second phase objects (Fig. 1, DP1 and DP2), while higher temperature leads to banded structures (Fig. 1, DP3 and DP4).

As can be seen in Fig. 2, besides the formation of banded structures for higher cooling temperature observed in the light optical microscope, the substructure of the second phase regions changes as well. With increasing cooling temperature from DP2 to DP3, a slight change in the substructure and in the morphology of the second phase can be seen.

\subsection{Light optical serial sectioning tomography}

The simulations were performed on real microstructures using DP1 and DP3 light microscope tomographies. DP2 and DP4 serve as a validation for the generation of virtual microstructures in Sect. 5.2. The tomographies 

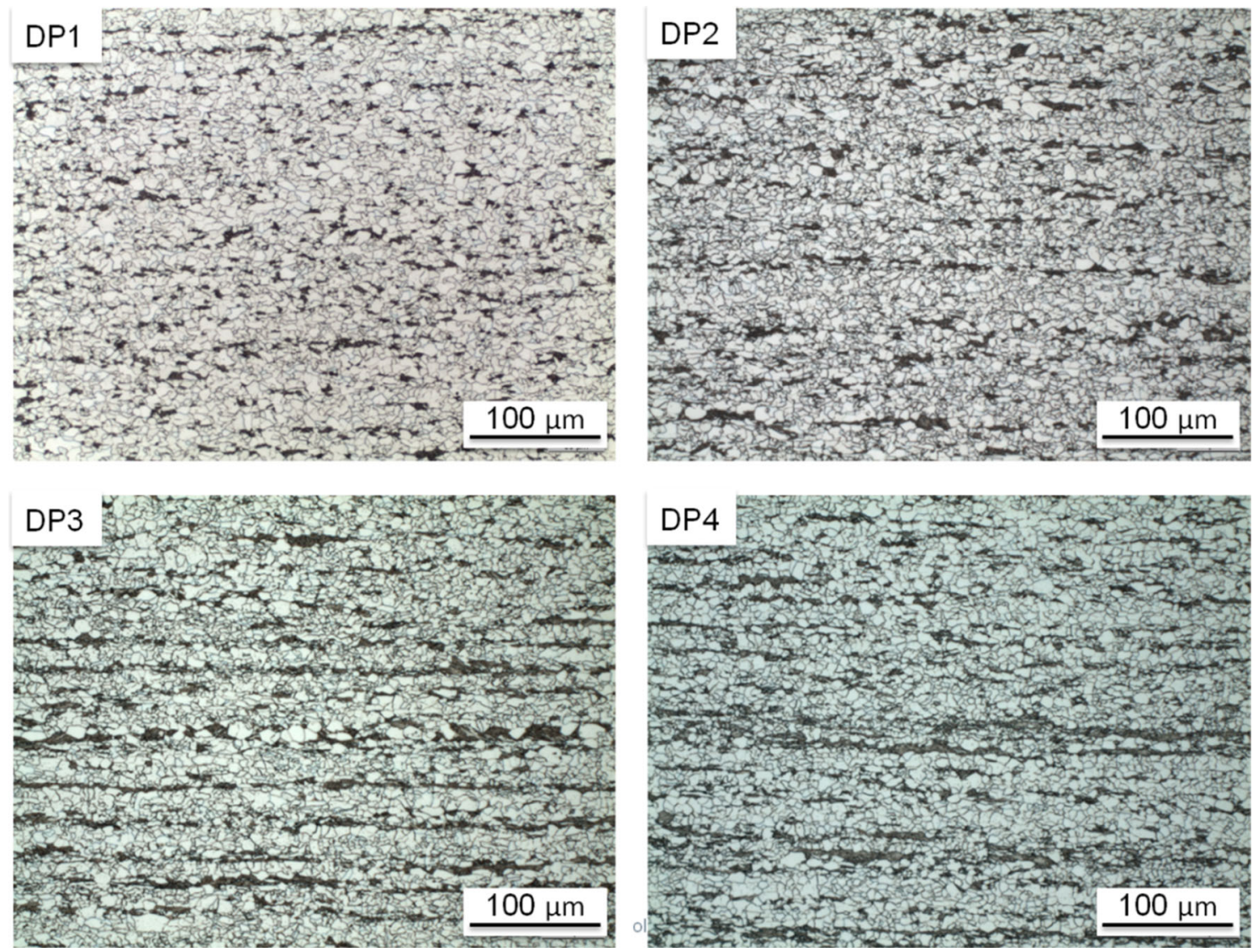

Fig. 1 Light microscopic images of the four samples after Nital etching with different cooling conditions DP1, DP2, DP3 and DP4. In addition to the second phase (dark areas), the grain boundaries of the matrix are also clearly visible
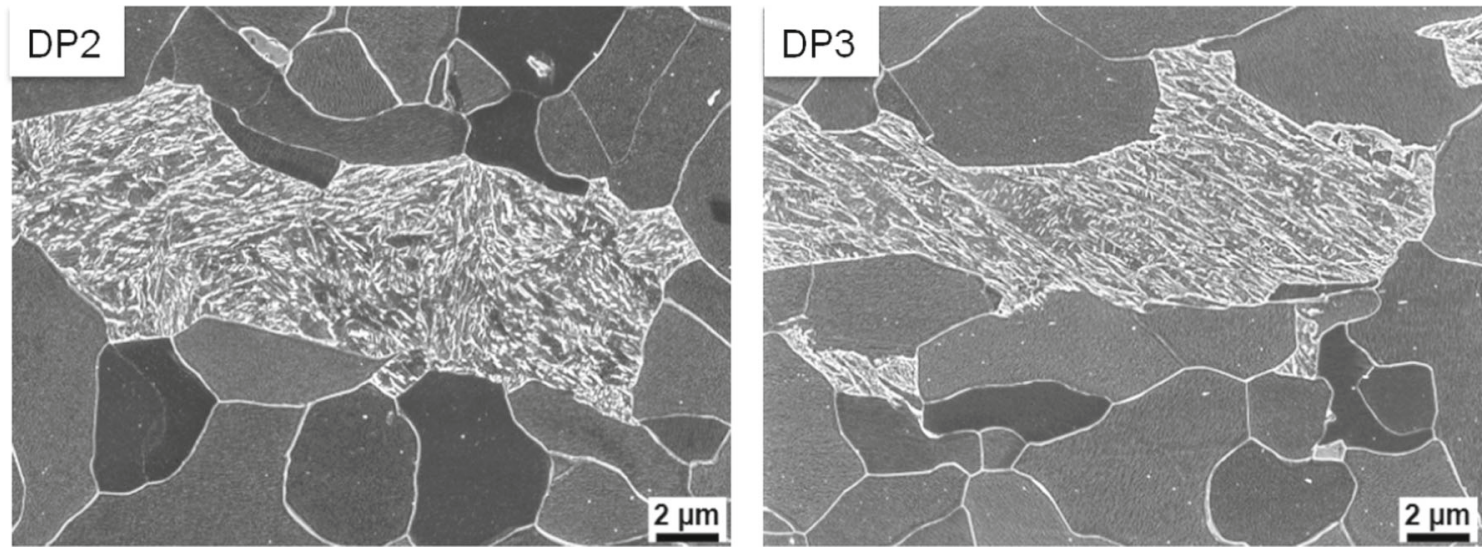

Fig. 2 SEM image of samples DP2 and DP3 after Beraha etching according to [62] in SE contrast to show the substructure

were produced using the set-up invented by Mücklich et al. [63], where a light microscopy serial sectioning tomography with etching and imaging in one system became possible. The tomography was performed on a modified set-up based on a Leica TXP target preparation machine for the material removal and a digital light optical microscope (LOM) VHX 2000 for imaging. The contrasting was performed also within the set-up with a Beraha etching. Because several hundred polishing and etching steps were carried out during the tomography, the sample was fixed on a custom made sample holder of the TXP machine with the embedding material DemoTec 15+. The following steps were repeated to capture the image of a cut: polishing, cleaning, etching, 


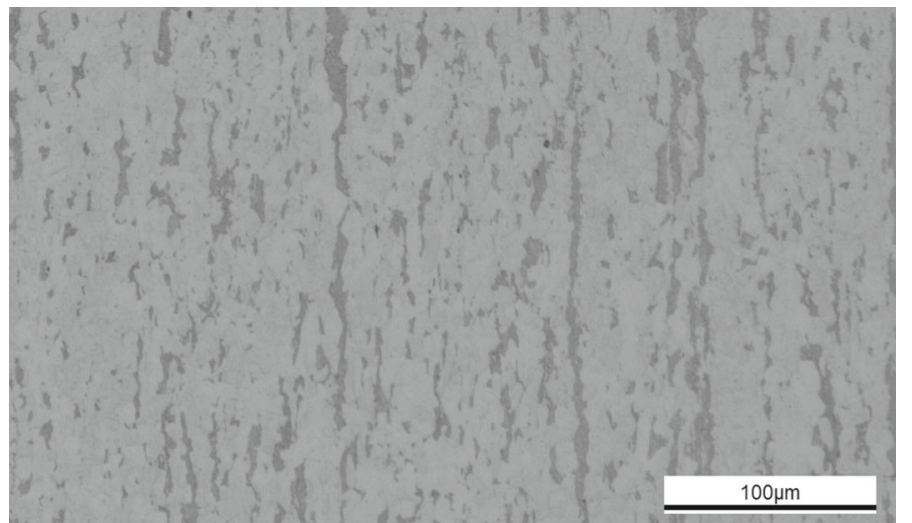

Fig. 3 Exemplary representation of a light microscopy image for the Beraha etched DP3 sample, with ferrite in light grey and second phase objects in dark grey

cleaning, and light microscopy image recording. For material removal, the polishing suspension MasterPrep (MP) with diamond particles and an average diameter of $0.05 \mu \mathrm{m}$ was used on a neoprene cloth. The removal rate of approximately $400 \mathrm{~nm}$ during tomography was set using a polishing force (pressing force) of $30 \mathrm{~N}$, the speed of the polishing disc of $400 \mathrm{RPM}$, a polishing time of $3 \mathrm{~min}$ and $2 \mathrm{ml}$ of the polishing suspension. The etching process was based on the investigations of Britz et al. [62]. A modified Beraha etchant consisting of $3 \mathrm{~g}$ potassium metabisulfite and $100 \mathrm{ml}$ deionized water was used to contrast the sample. With short etching times up to a minute, the second phase substructure was etched stronger than the grain boundaries of the surrounding ferrite grains. This leads to a well-contrasted second phase, while the boundaries of the ferrite grains were still not visible in the LOM and no significant removal took place during etching (Fig. 3) [62].

After the image acquisition, an image stack of 426 images for the sample DP1 with $424 \times 928$ pixels and a pixel size of $409 \mathrm{~nm} \times 409 \mathrm{~nm}$ can be used for the reconstruction of the tomography. For the sample DP3, 307 images of $631 \times 705$ pixels with the same pixel size are provided. Both tomographies thus have a representative size according to the analysis of Mücklich et al. [32].

In order to create a 3D reconstruction of the images, the images have to be aligned. For this the program Thermo Scientific Amira ${ }^{\circledR}$ was used. The images were aligned by a fixed mark on the sample that was prepared before the tomography process. Cuts were set on their original z-position calculated by the removal per cut. The second phase objects were separated from the ferritic matrix by a threshold value segmentation, which was carried out on the light microscopic images after standard filters such as shading correction and denoising were applied. Filters like dilatation were used on the binary images, in order to remove artefacts and errors. Additionally, all objects on the binary images that only occurred in one cut were removed, because they are artefacts due to polishing. To get isotropic voxels, the binary images were interpolated to a $z$-distance of $409 \mathrm{~nm}$.

Subsequently, the 3D representation of the tomography was visualized with the help of 3D reconstruction programs, Mavi (version 4.4) and Amira, wherein the connectivities of individual phases and components were made visible. The Mavi program offers implemented algorithms for processing volume images that can be used for quantitative microstructural analysis. It provides the possibility that all objects connected in the volume can be represented in the same colour (so-called labels). In order to characterize a structure in 3D based on its morphology, four parameters are necessary: the volume density, the surface density, the curvature integral density and the object density [64]. These quantities are implemented in Mavi and can be calculated from the fully reconstructed tomographies. Table 1 lists the volume-based parameters used for evaluation.

In the program Amira, labelled images can be visualized and information about the connectivity of the structures can be obtained, as shown in Fig. 4 for a representative volume with an edge length of $100 \mu \mathrm{m}$ of the samples DP1 and DP3. While individual second phase objects are identifiable in the visualization of the DP1 sample, in contrast to this, the 3D representation of the DP3 sample clearly shows the band-like structures with high connectivity. 
Table 1 Name and meaning of the volume-based parameters used for evaluation

\begin{tabular}{lll}
\hline Parameter & Symbol & Meaning \\
\hline $\begin{array}{l}\text { Volume density } \\
\text { Surface density }\end{array}$ & $V_{r}$ & $\begin{array}{l}\text { Ratio of the total volume of all second phase objects } \\
\text { to the total volume of the tomography } \\
\text { Ratio of the total surface of all second phase objects } \\
\text { to the total surface of the tomography } \\
\text { Ratio of the mean curvature of all second phase } \\
\text { objects to the total volume of the tomography } \\
\text { Ratio of the number of second phase objects } \\
\text { to the total volume of the tomography }\end{array}$ \\
\hline
\end{tabular}
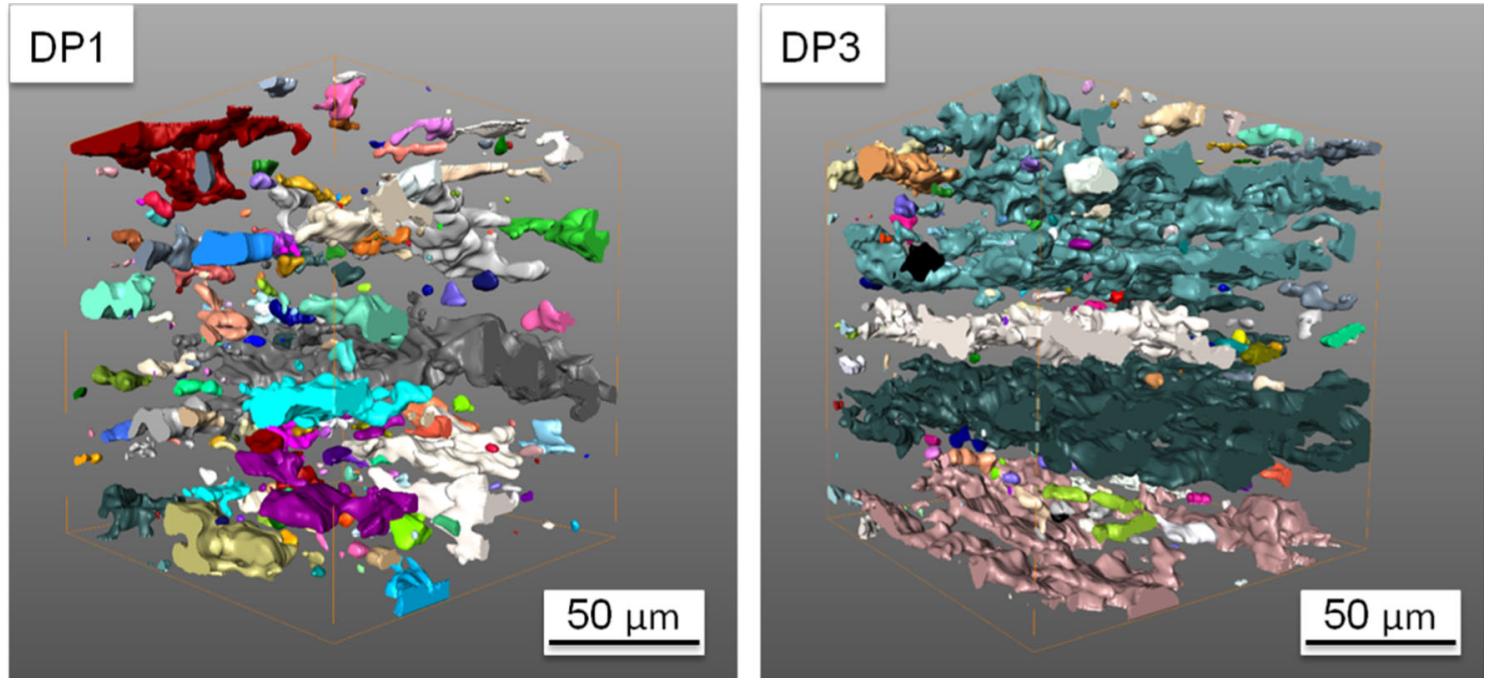

Fig. 4 Visualization of the reconstruction of the labelled image stack of the DP1 sample and the DP3 sample. In the visualization of the light microscopic tomographies second phase objects connected in volume are shown in the same colour

\subsection{Single-phase properties}

The material parameters used for the microstructure-based simulation are decisive for a realistic representation of the overall material properties. However, classical macroscopic material testing to determine the material parameters is not possible at the individual phases of the microstructures due to their small size. One possibility of determining the material parameters is the generation of tensile test specimens with properties analogous to the individual phases [3]. For this purpose, two new steels would have to be produced in a complex process by changing the alloy composition and process chain. The aim is to create a homogeneous microstructure which corresponds to one of the phases of the dual-phase steel in terms of chemical composition and structural composition. These analogue samples can then be examined by means of classical material testing and the properties of the individual phases can thus be determined. Due to the tremendous effort involved to produce this kind of specimens for a material with such complex production conditions as thermomechanically rolled plates, this is not the method of choice. Instead, a method based on nanoindentation according to Chen et al. $[65,66]$ was used in this paper.

For this purpose, depth-sensing nanoindentations of the two phases of the dual-phase steel DP1, ferrite and martensite, were performed. The obtained force-displacement curves are shown in Fig. 5. Four different martensite grains and four different ferrite grains were each indented with a cube-corner tip in a force controlled process up to $3000 \mu \mathrm{N}$ on a Hysitron TriboIndenter. Even if a spherical tip may give more information due to its non-self-similar shape, the cube-corner tip was used because its relatively sharp tip is well suited if only one grain is to be indented. Ferrite shows a comparatively low dispersion of the resulting penetration depth attributable to its homogeneous structure. This is in contrast to the hard martensite phase, which shows a higher relative dispersion than ferrite at lower indentation depth levels due to its heterogeneous structure. For further use, the mean value of all indents is considered for both phases. Based on these results, a parameter identification is performed (Sect. 3.1). 


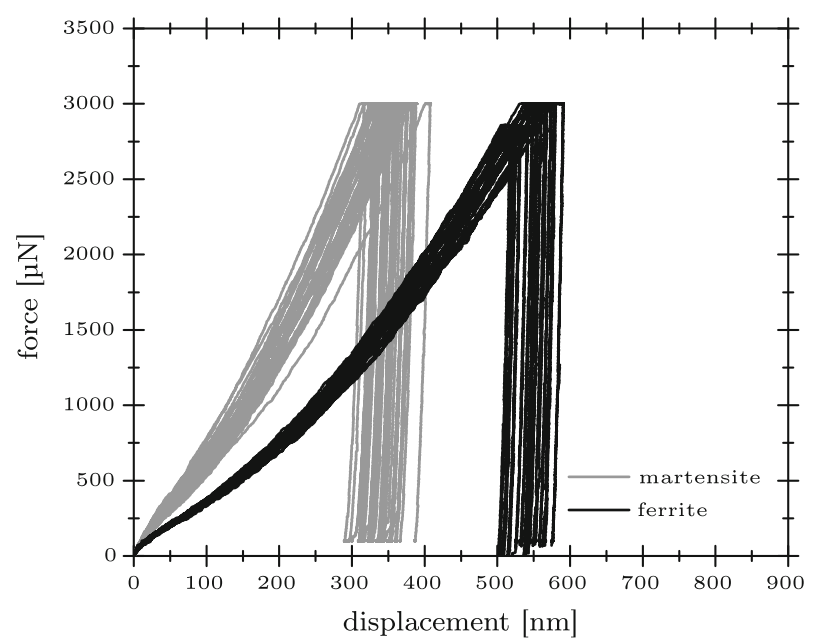

Fig. 5 Force-displacement curves of the ferrite phase (left) and the martensite phase (right) of DP1 in nanoindentation

\section{Numerical methods}

In the following section the numerical methods used in this work are explained. The description is divided into the parameter identification for the single phases, the implementation of the mechanical behaviour of dual-phase steel in the context of FEM and the created routine for the generation of virtual microstructures.

\subsection{Single-phase properties}

The material parameters of the individual phases are determined by inverse methods [66,67]. The process of nanoindentation is replicated by a standard elastoplastic material model in the commercial FEM program Simulia Abaqus FEA ${ }^{\circledR}$ as described by [66], because the program deal.II [60,61], used in the rest of the work, is not designed for multi-body contact problems. Since a large number of simulations are carried out within the framework of parameter identification, the Abaqus model is reduced to two dimensions. The 3D cubecorner tip is regarded as a rotationally symmetrical cone section. The opening angle of the cone is selected so that the ratio of contact surface to penetration depth of the cone corresponds to that of the cube-corner tip. This simplification reduces the simulation time from over $30 \mathrm{~min}$ to less than a minute. ${ }^{1}$ In the simulation, the displacement of the indenter is applied as a boundary condition and the resulting force is calculated. Furthermore, the assumption is made that the main deformation zone of the nanoindentations lies exclusively in the respective phase under consideration. Thus, in the simulation ferrite and martensite are each regarded as a homogeneous, single-phase material. They are modelled by an isotropic elastic-plastic material model with isotropic linear hardening as implemented in Abaqus.

With the help of this simulation model, an parameter identification was performed. Starting from an initial parameter set, a simulation is carried out and the resulting target quantity, here the force-displacement curve, is compared with the target quantity from the experiment. In the comparison, the normalized mean absolute error

$$
\Delta \mathrm{F}=\frac{1}{n} \sum_{i=1}^{n} \frac{\left\|F_{i}^{\mathrm{sim}}-F_{i}^{\mathrm{exp}}\right\|}{\left\|F_{i}^{m}\right\|}
$$

is used to quantify the deviation between experiment and simulation, where $n$ is the number of measurement points, $F^{\operatorname{sim}}$ the force value from the simulation, $F$ the force value from the experiment and $F^{m}$ their mean value. Based on the score of the fit value and the currently selected parameters, a new, adjusted parameter set is then determined with the help of an optimization algorithm. For this a Nelder-Mead simplex algorithm [68-70] implemented in MathWorks Matlab ${ }^{\circledR}$ is used. This process is carried out iteratively until a parameter set is found for which the fit value is less than a certain tolerance. Table 2 in Sect. 4.1 summarizes the mechanical parameters obtained for both phases.

\footnotetext{
${ }^{1}$ Computation time on a workstation with Intel Xeon E5-2630v3 CPU.
} 


\subsection{FE model}

An elastoplastic model for small strains was chosen to describe the material behaviour [71-73]. Accordingly, the strain tensor is additively split

$$
\boldsymbol{\varepsilon}=\boldsymbol{\varepsilon}_{e}+\boldsymbol{\varepsilon}_{p} .
$$

The elastic part model follows Hooke's law for the engineering strain $\sigma$ and the elastic part of the engineering strain $\boldsymbol{\varepsilon}_{e}$

$$
\boldsymbol{\sigma}=2 \mu \boldsymbol{\varepsilon}_{e}+\lambda \operatorname{tr}\left(\boldsymbol{\varepsilon}_{e}\right) \mathbf{I},
$$

with the Lamé parameters $\mu$ and $\lambda$ and the identity matrix $\mathbf{I}$. For the plastic part of the model, a standard $J_{2}$ von Mises plasticity model is used with linear isotropic hardening and associated flow rule [74]. The yield function is

$$
g=\left\|\sigma_{\mathrm{D}}\right\|-\sqrt{\frac{2}{3}}\left(\sigma_{y}-K \alpha\right),
$$

with the deviatoric stress tensor $\sigma_{\mathrm{D}}$, the initial yield strength $\sigma_{y}$, the hardening modulus $K$ and the flow parameter $\alpha$.

In order to model 3D RVEs for the different dual-phase steels, the voxel information from the binarized tomographies are directly transferred to a FEM mesh without further preprocessing. This requires a certain data compression described in [75] and implemented in the open source C++ program library deal.II [60,61]. Therefore, deal.II is used for further investigations instead of the aforementioned Abaqus and it is used to implement the described material model in the context of FEM. Based on the weak form of the stationary balance of momentum Newton's method is applied to calculate the solution iteratively. Despite the straightforward form of the material model, in this context a numerical tangent [76,77] is utilized instead of the analytical derivative of the balance of momentum. This decision is due to the realization of high variability of the implemented code with regard to extensions. For the treatment of plasticity, the Radial Return Method [74,78-80] is implemented. Again, for the sake of variability, the derivative of the flow rule with respect to the plastic increment is calculated by finite differences.

Even if the global deformation is limited to a strain below $10 \%$, the locally resolved computations used in this paper show that close to the phase boundaries in the heterogeneous microstructure finite strains may occur. Therefore, as a method of verification of the calculation, a compressible neo-Hookean model for finite deformation [81-84] was additionally implemented. For the Cauchy stress tensor $\mathbf{T}$ as a stress measure the following relationship applies:

$$
\mathbf{T}=\frac{\mu}{J}\left(\mathbf{B}_{e}-\mathbf{I}\right)+\frac{\lambda}{J} \ln J \mathbf{I},
$$

with the elastic part of the left Cauchy-Green deformation tensor $\mathbf{B}_{e}$ and the Jacobi determinant $J$ as deformation measures. More detailed information on the derivation and meaning of these quantities can be found in the literature $[82,83,85]$. The plastic part of the deformation is again implemented with linear, isotropic hardening using Radial Return Method. In the finite case, the calculation of the elastic part of the deformation is no longer based on the additive splitting (Eq. 2), but on the multiplicative split of the deformation according to Kröner and Lee $[74,86,87]$. Due to the nonlinearity of material models for finite deformations, the elastic test state of the Radial Return Method is calculated in a separate Newton method. This makes the model for finite deformations considerably more computationally intensive. However, as shown in Sect. 4.2, especially Fig. 9, the finite strains do not affect the overall behaviour and the finite deformation model does not show advantages over the small strain model for the use case under consideration.

\subsection{Structure generation}

To create the virtual microstructures, the open source program Dream.3D [88-90] is used. The program consists of a multitude of data processing routines, called filters, which are variably interconnected to a problem-specific process in a pipeline. In the presented work, this is used for the generation of virtual twophase microstructures based on ellipsoidal martensite regions. The structures are determined by the geometric 


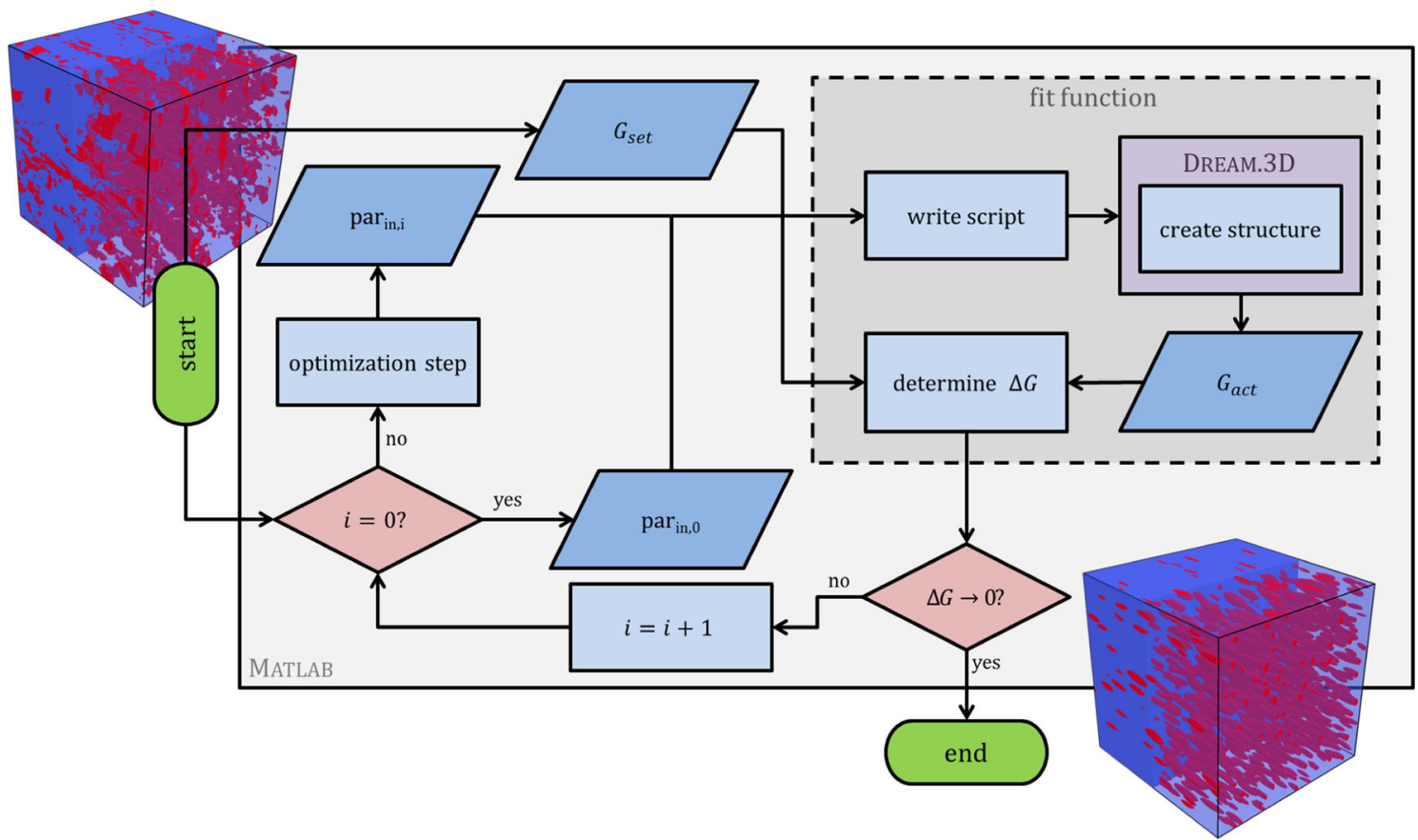

Fig. 6 Flowchart of the implemented routine for creating virtual structures. On the left, a section of the real microstructure of DP1 is shown as input variable and on the right the corresponding virtual microstructure as output variable

properties of the martensite areas. The relevant input parameters for the structure generation are the volume fraction of martensite, the parameters of the beta distribution of the ellipsoid axis ratios and the parameters of the logarithmic normal distribution of the equivalent sphere diameter of the ellipsoids. The orientation of the main axis of the ellipsoids is fixed according to the rolling structure of the steel. This results in a set of parameters of the phase structure par $_{\text {in }}$ as variable input values for Dream.3D. The parameters par $_{\text {in }}$ serve only for the control of Dream.3D; the geometry in comparison with the real microstructure or in relation to a desired target structure is evaluated via the geometry parameters volume fraction $V_{r}$, surface density $S_{r}$, curvature integral density $C_{r}$ and particle density $P_{r}$, as introduced in Table 1 . Since $V_{r}$ and $S_{r}$ have a stronger influence on the mechanical properties of the resulting structures, the geometry parameters for calculating the deviation of a virtual structure from the target geometry are weighted by phenomenological factors, determined for the steel under consideration in previous work [75]. The mean relative deviation $\Delta G$ of the geometry parameters is calculated as the weighted mean value of the relative deviations of the individual geometry parameters

$$
\Delta G=0.64 \Delta V_{r}+0.22 \Delta S_{r}+0.07 \Delta C_{r}+0.07 \Delta P_{r}
$$

The process of structure generation in Dream.3D is embedded in an optimization routine implemented in Matlab (Fig. 6) for the fully automatic determination of virtual structures. The starting point for the structure creation is a reference parameter set $G_{\text {set }}$. These parameters can either be determined in the program itself on the basis of an image stack of the tomography of a real structure or they can simply be specified as target values. Beginning with a start parameter set par $_{\text {in, },}$, a control script for Dream.3D is created in the fit function. In Dream.3D, this script creates the statistics of the phase geometry, generates the individual phase ranges accordingly and exports the resulting phase structure. The virtual structure is then read into Matlab in the fit function and the geometry parameters $G_{\text {act }}$ and their deviation $\Delta G$ from the nominal value are determined. If $\Delta G$ is significantly larger than a given tolerance, a new parameter set par $_{\mathrm{in}, i}$ is determined in an optimization step and the fit function is run again. The parameter optimization is again performed by a Nelder-Mead simplex algorithm [68-70] implemented in Matlab. The process is run through iteratively until $\Delta G$ is sufficiently small. The resulting virtual structure is then accepted as the final structure and investigated in the mechanical simulation. As for the microstructures obtained by tomography, the virtual structures generated by this routine are transferred to a hexahedral FEM mesh without further preprocessing for this purpose. 
Table 2 Identified material parameters of the phases of DP1

\begin{tabular}{lll}
\hline & Ferrite & Martensite \\
\hline$\mu(\mathrm{GPa})$ & 89.5 & 91.7 \\
$\lambda(\mathrm{GPa})$ & 173.7 & 141.0 \\
$K(\mathrm{GPa})$ & 1.70 & 2.96 \\
$\sigma_{y}(\mathrm{MPa})$ & 401 & 1081 \\
\hline
\end{tabular}

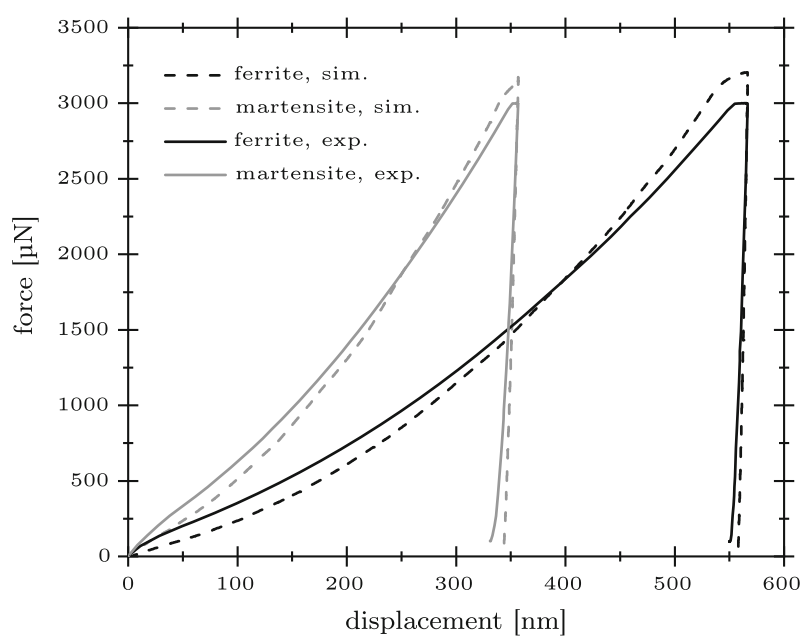

Fig. 7 Comparison of the mean value of the experimental nanoindentations with the optimized simulation result for ferrite and martensite

\section{Results for real microstructures}

\subsection{Single-phase properties}

For the nanoindentation experiments on DP1, the material parameters in Table 2 are obtained following the above-mentioned parameter identification process. The corresponding force-displacement curves of the nanoindentation are shown in Fig. 7. Both simulations for ferrite and martensite, respectively, hit the mean of the respective experimental curves very well. Additionally, the identified Young's moduli for ferrite and martensite, $238 \mathrm{MPa}$ and $239 \mathrm{MPa}$, are comparable to the mean Young's moduli determined by Oliver-Pharr method [91] from the single nanoindentation experiments, $200 \mathrm{MPa}$ and $213 \mathrm{MPa}$. Thus, the set of material parameters determined for the individual phases is used for the microstructure-based simulation of the tensile test as material parameters for the two phases of the dual-phase steel.

For the sake of completeness, it should be noted that the parameter identification procedure used here is not universally valid. A cube-corner indenter is self-similar due to its tetrahedral shape. As a result, the deformation field around the indenter tip, apart from variations due to edge rounding, only increases in size during indentation, while the strain distribution itself remains the same. Self-similar indenter tips are less suitable for parameter identification than non-similar forms such as spherical indenters, since the constant deformation field provides too little information for an unambiguous determination of the parameters [66,92, 93]. However, this effect can be neglected here, since on the one hand, the parameter space has been limited to values that are physically realistic for steel, and on the other hand, the material parameters determined here provide a realistic result even in the completely different deformation situation of the tensile test as shown in the next subsection.

\subsection{Mechanical simulation of tensile tests on real microstructures}

The aim of this work is the realistic simulation of dual-phase steel by incorporating its phase structure. In the following, the developed simulation model will be validated on two real microstructures. Additionally, the approach is verified using an alternative material model. 

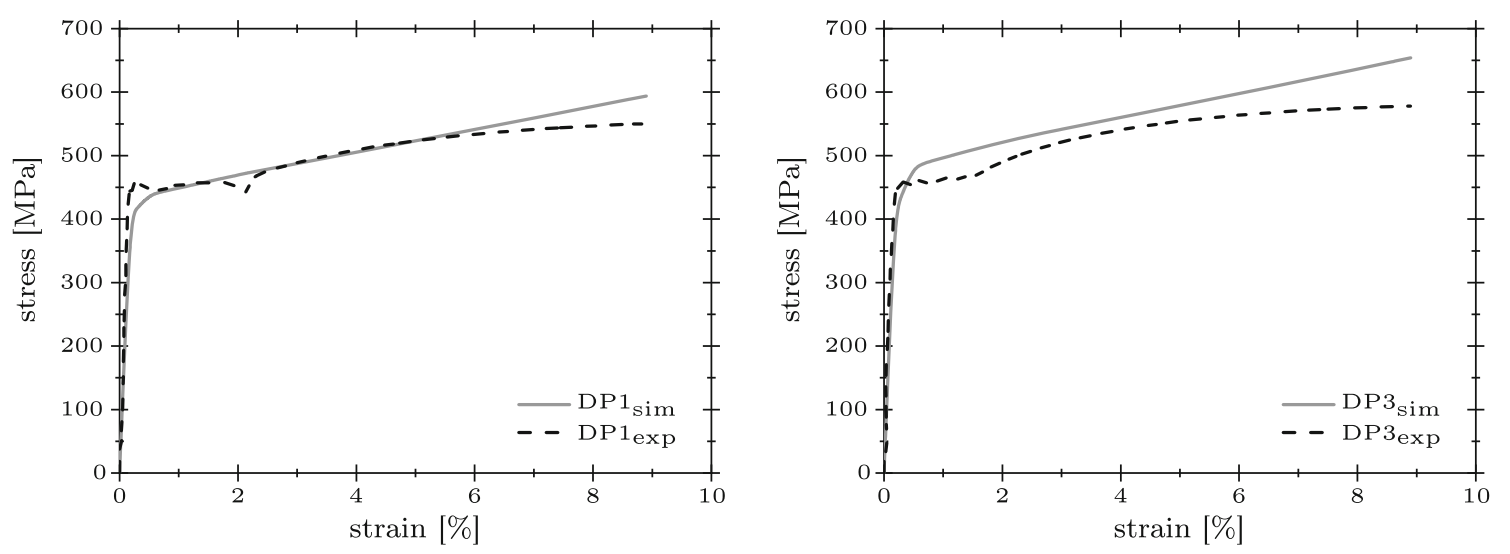

Fig. 8 Stress-strain diagram for a tensile test and the corresponding simulation on DP1 and DP3

The comparison of the simulated tensile test with the real experiment is the most important point of the validation of the simulation model. Figure 8, left, shows the stress-strain diagrams for DP1, each with tension transverse to the rolling direction, for the experiment and the simulation. DP1 is the steel used to develop the model. Both curves show good correspondence overall. The differences are mainly limited to the area of Lüders strain in the transition between elastic and plastic material behaviour. The Lüders strain can in principle not be mapped with the help of the phase-structure-based simulation implemented here. For this, the simulation model would have to include the underlying small-scale effect of trapping and dynamic release of dislocations at impurity atoms via the direct consideration of dislocations. Alternatively, Lüders strain could be defined purely phenomenologically as an area of ideal plastic deformation at the beginning of the plasticity. Both variants were not considered for this study in favour of a realistic and efficient simulation of the remaining course of the stress-strain diagram. The simulated stress-strain diagram follows the experimental tensile curve very closely from the Lüders strain range on. Only for higher strains above 7\% the curves start to diverge slowly. In this area, the experimental tensile curve reaches its stress plateau, which cannot be reproduced by the model due to the underlying assumptions of linear hardening. From here, effects such as sample necking and damage begin to take effect which are not considered in this paper. Overall, the experimental tensile curve in the relevant deformation range less than $10 \%$ strain is very well covered. In theory a nonlinear hardening model, e. g. a Voce-type hardening model, could fit the partially curved shape of the stress-strain diagram even better. Yet, in [75] it was proven, that taking into account exponential hardening in the model will not increase the overall accuracy. Most likely this is due to overfitting of the nanoindentation, as the parameters were obtained by the nanoindentation results.

The development of the numerical model and the determination of the properties of the individual phases were carried out on DP1. However, the model is designed to also carry out simulations on the basis of other microstructures. Therefore, a simulation based on the tomography of another steel (DP3) serves as additional validation of the simulation model. Apart from the changed microstructure, the simulation is completely analogous to the simulation at DP1. A comparison of the stress-strain diagrams (Fig. 8, right) shows a lesser accordance between simulation and experiment for DP3 than for DP1. However, the deviation of the curves for DP3 is still small. For example, $R_{t 5.0}$, the mean stress at $5 \%$ total strain, has a deviation of about $4 \%$. Only for higher elongations above 7\%, the deviation starts to rise more strongly. In this area however, the difference between simulation and experiment is also greatest in DP1. The slightly increased deviation of simulation and experiment for DP3 compared to DP1 can be easily explained. The properties of the individual phases vary slightly between DP1 and DP3. Both steels differ in their manufacturing process, but not in their chemical composition. Nevertheless, DP3 contains about twice as much carbon-rich second phase as DP1. Correspondingly, the micrograph shows that the carbon-rich second phase of DP3 is not a typical martensite. Since carbon is critical to the strength of steel, this change in the distribution of carbon causes a change in the properties of the individual phases. Overall, however, the shape of the stress-strain diagram from DP3 as well as the trend of the increasing stress level from DP1 to DP3 can be well represented with the simulation carried out here.

The present work uses a material model for small elastic deformations with linear hardening in the plastic range. This represents a simplification of the real material behaviour. As a verification, a compressible neoHookean material model was implemented based on kinematics for finite deformations. Figure 9 shows the 

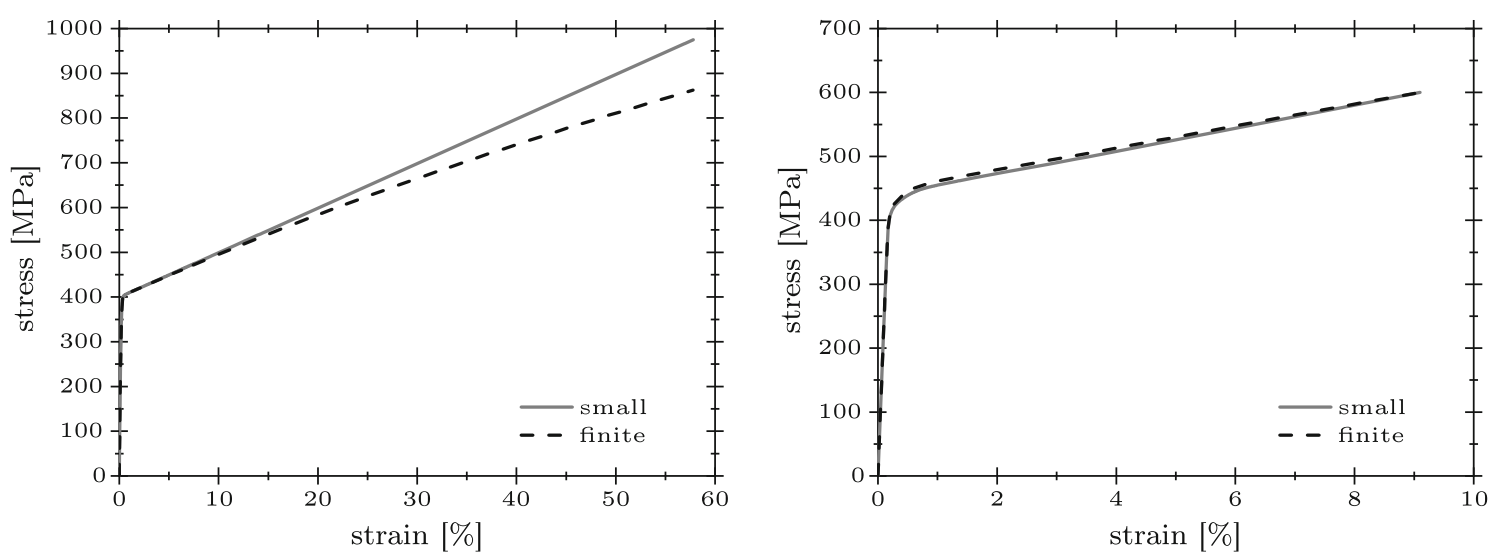

Fig. 9 Stress-strain diagram of a simulated tensile test for small and finite deformations in the range of large (left) and moderate (right) deformation

stress-strain diagram of the finite deformation model compared to the small deformation model. For high elongations, there are noticeable differences between the two models. The main reason for the differences is the neglect of higher order terms in the derivation of kinematics for small deformations. However, when macroscopic strains of less than $10 \%$ (Fig. 9, right) are considered, it becomes apparent that this simplification does not lead to any differences in the stress-strain diagram in the observed deformation range. Therefore, the small strain model is applicable in the strain region under consideration.

Consequently, the developed simulation model can well reproduce the real mechanical behaviour of dualphase steel in tensile tests. This applies both to the steel used for model development and to a second steel with differing microstructure. In addition, a more complex material model does not show a more precise adaptation to reality. Accordingly, the presented model is suitable for predicting the properties of virtual microstructures in the following section.

\section{Results for virtual microstructures}

The validation of the process for creating virtual structures (Sect. 3.3) takes place in two steps. First, the quality of the adaptation of virtual structures to existing tomographies is determined with regard to the geometry parameters and the flow curves, to show that the model is able to create suitable virtual microstructures for the known real microstructures. Second, the ability of the model to predict the mechanical properties of new microstructures on the basis of virtual structures is shown.

\subsection{Virtual structures for known real microstructures}

In the first part of the validation, the tomographies of DP1 and DP3 are given as target values to the structure generation process. Table 3 shows the geometric parameters of the real and virtual microstructures with their respective deviation $\Delta G$. The determined virtual structures match the corresponding real structures up to a deviation of about $1 \%$. The more strongly weighted parameters volume fraction and surface density are reproduced according to their weighting with very good accuracy, only the less significant curvature integral density and the particle density show a moderate deviation. Based on the virtual structures, tensile tests are simulated. Both virtual structures show a significant agreement in their stress strain diagrams (Fig. 10) with the corresponding real structures. For DP3, e.g.the deviation of $R_{t 5.0}$ between the simulation on the real microstructure and the virtual microstructure is approximately $1 \%$. According to the slightly more precise fit of the geometry parameters for DP1, the deviation of $R_{t 5.0}$ is even less than $0.5 \%$. All in all, the generated virtual microstructures, as shown in Fig. 6 for DP1, represent the real microstructures very accurately, both in terms of geometry and mechanical properties. These investigations thus show that the method developed for the generation of virtual microstructures is highly suitable for reproducing virtual structures corresponding to a known microstructure. 
Table 3 Geometry parameters of the real structures (index ${ }_{r}$ ) of DP1 and DP3 as well as the associated virtual microstructures (index $)_{v}$

\begin{tabular}{lcclll}
\hline & $V_{r}(\%)$ & $S_{r}\left(10^{5} \mathrm{~m}^{-1}\right)$ & $C_{r}\left(10^{9} \mathrm{~m}^{-2}\right)$ & $P_{r}\left(10^{14} \mathrm{~m}^{-3}\right)$ & $\Delta G(\%)$ \\
\hline $\mathrm{DP}_{r}$ & 8.34 & 89,778 & 3.44 & 3.50 & 1.08 \\
$\mathrm{DP}_{v}$ & 8.34 & 88,019 & 3.60 & 4.16 & 1.42 \\
$\mathrm{DP}_{r}$ & 17.13 & 165,350 & 4.90 & 5.68 & 5.59 \\
$\mathrm{DP}_{v}$ & 17.17 & 166,703 & 5.29 & & \\
\hline
\end{tabular}
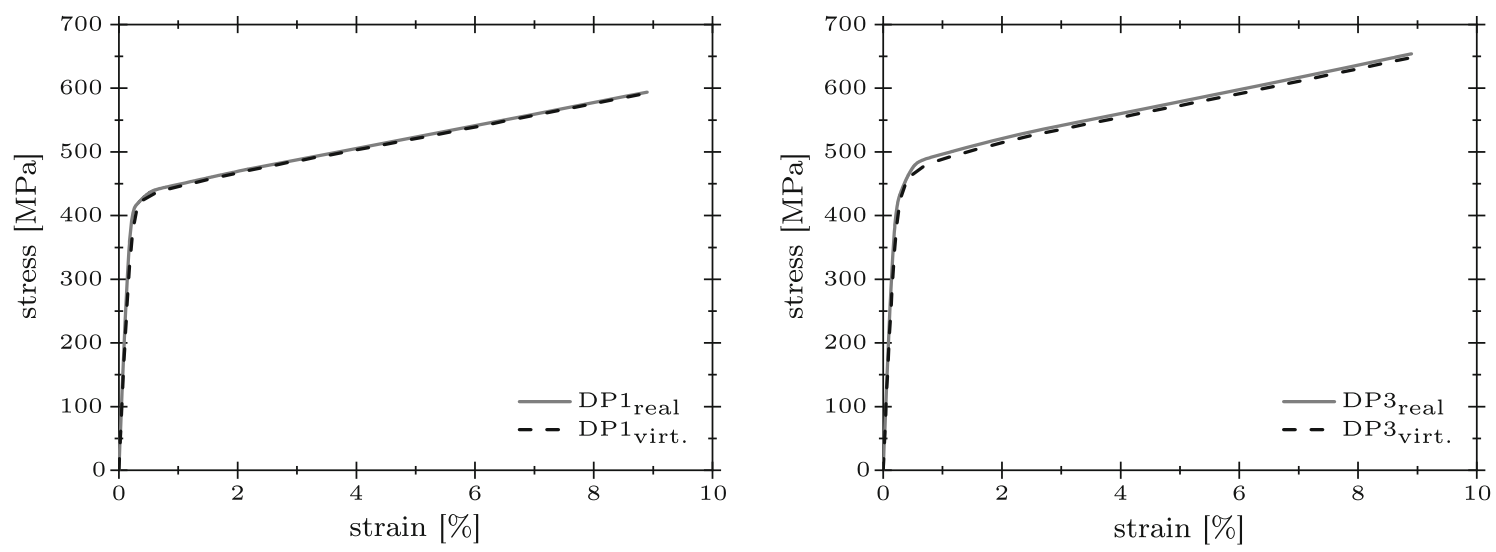

Fig. 10 Stress-strain diagram for a simulated tensile test of the real structure and the associated virtual microstructure of DP1 (left) and DP3 (right)

\subsection{Investigation of new microstructures}

The creation of virtual microstructures according to a real and known microstructure is only an intermediate step of the structure generation for validation purposes. The main goal of the structure generation in the context of the presented work is the creation of new virtual microstructures not yet known by tomographies. The investigation of the steels DP2 and DP4 serves this purpose. The mechanical behaviour of both steels is known from uniaxial tensile tests, but in contrast to DP1 and DP3, no 3D microstructure information is available from tomographies. Only the volume fraction of martensite was determined from 2D micrographs. Surface density, curvature integral density and particle density are also required to generate the corresponding virtual structures. They are interpolated and respectively extrapolated from the values of DP1 and DP3 according to their martensite volume fractions. For DP1 and DP3, $V_{r}$ does not only correspond to the tomography, but to the joint mean value of the tomography and the microsections for statistical purposes. The four parameter sets determined in this way are specified as the target value of the structure generation and corresponding virtual microstructures are created. As an example, a 2D section of the real microstructure of DP2 and the corresponding virtual microstructure is shown in Fig. 11. Even though the two structures do not look completely similar at first glance, the geometry parameters of the virtual structures show good agreement with the target values (Table 4). The difference in $\Delta G$ lies in the range between $1.99 \%$ for DP4 and $3.11 \%$ for DP2. Based on these virtual structures, tensile tests are simulated and their results are compared with the respective experiments (Fig. 12). The value $R_{t 5.0}$, the mean stress at $5 \%$ total strain, is used for comparison. The simulations show a very good agreement with experiments. The maximum deviation for DP3 is $2 \%$, all other simulations have a deviation from the experiment of less than $1 \%$. Accordingly, the simulation model and the routine for generating virtual structures are capable of predicting the mechanical properties of dual-phase steels only based on a single 2D microsection with high accuracy.

\section{Conclusion}

In the presented paper, the entire process chain for the microstructure-based simulation of dual-phase steel was described comprehensively. The material was modelled as a two-phase linear elastic continuum with linear hardening plastic behaviour. The material parameters used were determined by nanoindentation of the 


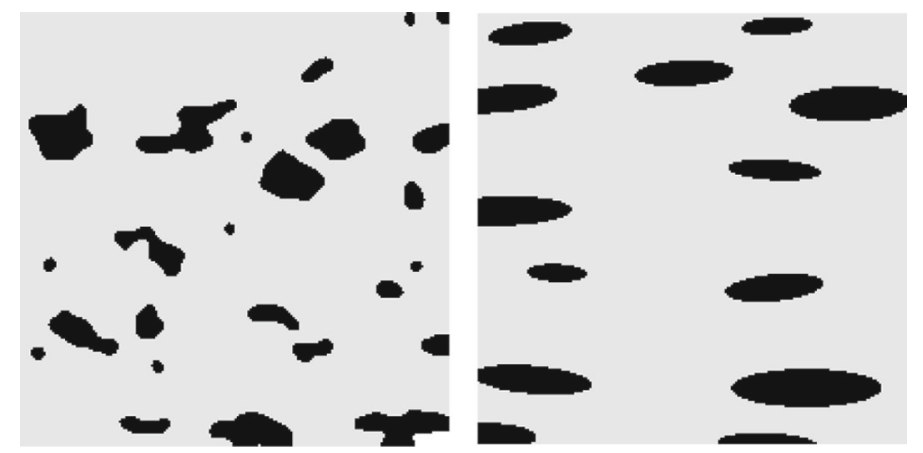

Fig. 11 Comparison of an exemplary 2D section of the real microstructure of DP2 (left) and the corresponding virtual microstructure (right) with an edge length of $80 \mu \mathrm{m}$. For DP2 no 3D tomography is available, and the virtual microstructure exclusively serves as 3D structure here

Table 4 Geometry parameters of the real structures of DP1, DP2, DP3 and DP4 as well as the corresponding virtual microstructures

\begin{tabular}{|c|c|c|c|c|c|}
\hline & $V_{r}(\%)$ & $S_{r}\left(10^{5} \mathrm{~m}^{-1}\right)$ & $C_{r}\left(10^{9} \mathrm{~m}^{-2}\right)$ & $P_{r}\left(10^{14} \mathrm{~m}^{-3}\right)$ & $\Delta G(\%)$ \\
\hline $\mathrm{DP} 1_{r}$ & 9.24 & 89,778 & 3.44 & 3.50 & 2.19 \\
\hline $\mathrm{DP} 1_{v}$ & 9.19 & 88,672 & 3.45 & 4.33 & \\
\hline $\mathrm{DP} 2_{r}$ & 9.75 & 95,733 & 3.55 & 3.67 & 3.11 \\
\hline $\mathrm{DP} 2_{v}$ & 9.69 & 93,166 & 3.80 & 4.61 & \\
\hline $\mathrm{DP} 3_{r}$ & 15.63 & 165,350 & 4.90 & 5.68 & 2.09 \\
\hline $\mathrm{DP} 3 v$ & 15.56 & 163,541 & 5.74 & 5.33 & \\
\hline $\mathrm{DP} 4_{r}$ & 16.46 & 175,111 & 5.09 & 5.96 & 1.99 \\
\hline $\mathrm{DP} 4_{v}$ & 16.37 & 168,269 & 5.22 & 5.46 & \\
\hline
\end{tabular}

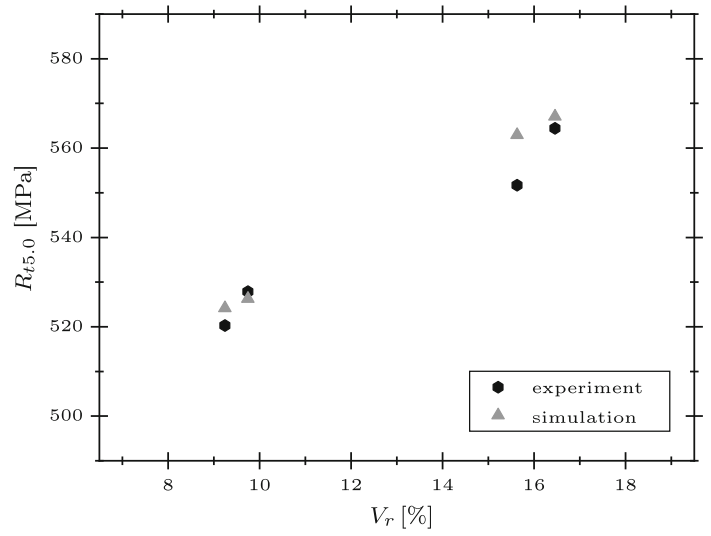

Fig. 12 Comparison of the experimentally determined $R_{t 5.0}$ values with the values simulated on virtual microstructures for DP1, DP2, DP3 and DP4 as a function of the given martensite volume fraction

individual phases of the steel and numerical parameter identification using inverse methods. To confirm the assumption of linear kinematics, a model for finite deformations was additionally implemented. However, it showed no advantages over the chosen geometrically linear material model in the strain range considered in the paper.

The comparison of the simulation routine developed considering a dual-phase steel microstructure (on the basis of which the process was developed), showed very good agreement with the experiment. Moreover, the simulation of a similar dual-phase steel, possessing a new microstructure (unbeknown to the simulation process), showed only a slight deviation from the experiment. Thus, the ability of the implemented simulation could be confirmed to realistically reproduce the mechanical properties of dual-phase steel on the basis of its microstructure.

The last point dealt with in the paper was the generation of virtual microstructures. On the basis of ellipsoidal structures, virtual structures were generated in an optimization process which were adapted in their geometric 
properties to real microstructures. It could be shown that the virtual structures generated in that way match the corresponding real microstructures from tomographies, both geometrically and in their mechanical behaviour in the simulation. Virtual structures for two further dual-phase steels, based on their martensite volume fraction and the two known microstructures, were also created. There was considerable agreement with the experiments on the two steels. As a consequence, the developed simulation process and the structure generation routine are suitable for predicting the flow curve of a dual-phase steel based on the parameters of the phase structure.

The models developed in this work now offer several approaches. On the one hand, similar dual-phase steels, which are only known from 2D microsections, can be modelled in 3D based on their microstructures. The generation of suitable virtual structures enables the comprehensive mechanical investigation in the simulation. On the other hand, the mechanical properties of similar, still unknown dual-phase steels can be determined. Thus, virtual structures can be created directly by the optimization process on the basis of the geometry parameters expected for the new steel. However, they can also be generated by bypassing the optimization by manually selecting the parameters in the implemented Dream.3D process and visually evaluating the resulting structures. Both procedures enable the creation of new dual-phase steel microstructures and the investigation of their mechanical properties in virtual tensile tests. A combination of mechanical simulation and structure generation in an optimization process offers further great potential. As a target parameter of the structure generation, the adaptation of the mechanical properties in the simulation to a desired behaviour is used. This allows to systematically determine the optimum microstructure for the desired mechanical properties. In the sense of reverse engineering, this structure can then be created during the production of the material.

Acknowledgements The authors thank Prof. Dr. mont. Christian Motz and his department Experimentelle Methodik der Werkstoffwissenschaften at Universität des Saarlandes for their support in the experiments on nanoindentation.

Open Access This article is licensed under a Creative Commons Attribution 4.0 International License, which permits use, sharing, adaptation, distribution and reproduction in any medium or format, as long as you give appropriate credit to the original author(s) and the source, provide a link to the Creative Commons licence, and indicate if changes were made. The images or other third party material in this article are included in the article's Creative Commons licence, unless indicated otherwise in a credit line to the material. If material is not included in the article's Creative Commons licence and your intended use is not permitted by statutory regulation or exceeds the permitted use, you will need to obtain permission directly from the copyright holder. To view a copy of this licence, visit http://creativecommons.org/licenses/by/4.0/.

\section{References}

1. Morgan Stanley: worldwide base metal production from 2007 to 2017, by commodity type (in million metric tons). https:// www.statista.com/statistics/241004/base-metal-production-by-type/ (05 Nov. 2018)

2. Tasan, C., Diehl, M., Yan, D., Bechtold, M., Roters, F., Schemmann, L., Zheng, C., Peranio, N., Ponge, D., Koyama, M., Tsuzaki, K., Raabe, D.: An overview of dual-phase steels: advances in microstructure-oriented processing and micromechanically guided design. Ann. Rev. Mater. Res. 45(1), 391-431 (2015)

3. Brands, D., Balzani, D., Scheunemann, L., Schröder, J., Richter, H., Raabe, D.: Computational modeling of dual-phase steels based on representative three-dimensional microstructures obtained from ebsd data. Arch. Appl. Mech. 86(3), 575-598 (2016)

4. Tarigopula, V., Hopperstad, O., Langseth, M., Clausen, A., Hild, F.: A study of localisation in dual-phase high-strength steels under dynamic loading using digital image correlation and fe analysis. Int. J. Solids Struct. 45(2), 601-619 (2008)

5. Ishikawa, N., Yasuda, K., Sueyoshi, H., Endo, S., Ikeda, H., Morikawa, T., Higashida, K.: Microscopic deformation and strain hardening analysis of ferrite-bainite dual-phase steels using micro-grid method. Acta Mater. 97, 257-268 (2015)

6. Ji, L.K., Li, H.L., Wang, H.T., Zhang, J.M., Zhao, W.Z., Chen, H.Y., Li, Y., Chi, Q.: Influence of dual-phase microstructures on the properties of high strength grade line pipes. J. Mater. Eng. Perform. 23(11), 3867-3874 (2014)

7. Li, R., Zuo, X., Hu, Y., Wang, Z., Hu, D.: Microstructure and properties of pipeline steel with a ferrite/martensite dual-phase microstructure. Mater. Charact. 62(8), 801-806 (2011)

8. Qin, J., Chen, R., Wen, X., Lin, Y., Liang, M., Lu, F.: Mechanical behaviour of dual-phase high-strength steel under high strain rate tensile loading. Mater. Sci. Eng. A 586, 62-70 (2013)

9. Tarigopula, V., Hopperstad, O., Langseth, M., Clausen, A.: Elastic-plastic behaviour of dual-phase, high-strength steel under strain-path changes. Eur. J. Mech. A Solids 27(5), 764-782 (2008)

10. Das, D., Protim Chattopadhyay, P.: Influence of martensite morphology on the work-hardening behavior of high strength ferrite-martensite dual-phase steel. J. Mater. Sci. 44, 2957-2965 (2009)

11. Davies, R.G.: Influence of martensite composition and content on the properties of dual phase steels. Metall. Trans. A 9(5), 671-679 (1978)

12. Kang, J., Ososkov, Y., Embury, J.D., Wilkinson, D.S.: Digital image correlation studies for microscopic strain distribution and damage in dual phase steels. Scr. Mater. 56(11), 999-1002 (2007)

13. Kim, S., Lee, S.: Effects of martensite morphology and volume fraction on quasi-static and dynamic deformation behavior of dual-phase steels. Metall. Mater. Trans. A 31(7), 1753-1760 (2000)

14. Rieger, F.: Work-hardening of dual-phase steel. Ph.D. thesis, Karlsruher Institut für Technologie (2015) 
15. Rieger, F., Wenk, M., Schuster, S., Böhlke, T.: Mechanism based mean-field modeling of the work-hardening behavior of dual-phase steels. Mater. Sci. Eng. A 682, 126-138 (2017)

16. Zienkiewicz, O.C., Taylor, R.L.: The Finite Element Method, vol. 36. McGraw-Hill, London (1977)

17. Hadwiger, H.: Vorlesungen Über Inhalt, Oberfläche und Isoperimetrie. Springer, Berlin, Heidelberg (2012)

18. DeHoff, R.: Quantitative serial sectioning analysis: preview. J. Microsc. 131(3), 259-263 (1983)

19. Diehl, M., Shanthraj, P., Eisenlohr, P., Roters, F.: Neighborhood influences on stress and strain partitioning in dual-phase microstructures. Meccanica 51(2), 429-441 (2016)

20. Desplentere, F., Lomov, S., Woerdeman, D., Verpoest, I., Wevers, M., Bogdanovich, A.: Micro-ct characterization of variability in 3d textile architecture. Compos. Sci. Technol. 65(13), 1920-1930 (2005)

21. Yan, C., Hao, L., Hussein, A., Young, P., Raymont, D.: Advanced lightweight 3161 stainless steel cellular lattice structures fabricated via selective laser melting. Mater Des 55, 533-541 (2014)

22. Zhou, H., Li, C., Zhang, L., Crawford, B., Milani, A.S., Ko, F.K.: Micro-xct analysis of damage mechanisms in 3d circular braided composite tubes under transverse impact. Compos. Sci. Technol. 155, 91-99 (2018)

23. Alkemper, J., Voorhees, P.W.: Quantitative serial sectioning analysis. J. Microsc. 201(3), 388-394 (2001)

24. Britz, D., Webel, J., Gola, J., Mücklich, F.: A correlative approach to capture and quantify substructures by means of image registration. Pract. Metallogr 54, 685-696 (2017)

25. Keehan, E., Karlsson, L., Bhadeshia, H.K.D.H., Thuvander, M.: Three-dimensional analysis of coalesced bainite using fib tomography. Mater. Charact. 59, 877-882 (2008)

26. Lasagni, F., Lasagni, A., Marks, E., Holzapfel, C., Mücklich, F., Degischer, H.: Three-dimensional characterization of 'as-cast' and solution-treated alsi12(sr) alloys by high-resolution fib tomography. Acta Mater. 55(11), 3875-3882 (2007)

27. Li, M., Ghosh, S., Rouns, T.N., Weiland, H., Richmond, O., Hunt, W.: Serial sectioning method in the construction of 3-d microstructures for particle-reinforced mmcs. Mater. Charact. 41(2), 81-95 (1998)

28. Roland, M., Kruglova, A., Gaiselmann, G., Brereton, T., Schmidt, V., Mücklich, F., Diebels, S.: Numerical simulation and comparison of a real al-si alloy with virtually generated alloys. Arch. Appl. Mech. 85(8), 1161-1171 (2015)

29. Buzug, T.M.: Computed Tomography: From Photon Statistics to Modern Cone-Beam CT. Springer, Berlin (2008)

30. Zajac, S., Schwinn, V., Tacke, K.: Characterisation and quantification of complex bainitic microstructures in high and ultrahigh strength linepipe steels. In: Rodriguez-Ibabe, J.M., Gutiérrez, I., López, B., Iza-Mendia, A. (eds.) Materials Science Forum, vol. 500, pp. 387-394. Trans Tech Publications (2005)

31. Uchic, M.D., Groeber, M.A., Dimiduk, D.M., Simmons, J.: 3d microstructural characterization of nickel superalloys via serial-sectioning using a dual beam fib-sem. Scr. Mater. 55(1), 23-28 (2006)

32. Mücklich, F., Engstler, M., Britz, D., Gola, J.: Serial sectioning techniques-a versatile method for three-dimensional microstructural imaging: the working group 'serial sectioning tomography' is headed by prof. Dr.-ing FrankMücklich. Pract. Metallogr. 55(8), 569-578 (2018)

33. Echlin, M., Pollock, T.: Femtosecond laser serial sectioning: a new tomographic technique. In: 8th World Congress on Computational Mechanics (2008)

34. Burnett, T., Kelley, R., Winiarski, B., Contreras, L., Daly, M., Gholinia, A., Burke, M., Withers, P.: Large volume serial section tomography by xe plasma fib dual beam microscopy. Ultramicroscopy 161, 119-129 (2016)

35. Calcagnotto, M., Ponge, D., Demir, E., Raabe, D.: Orientation gradients and geometrically necessary dislocations in ultrafine grained dual-phase steels studied by $2 d$ and 3d ebsd. Mater. Sci. Eng. A 527(10), 2738-2746 (2010)

36. Hill, R.: Elastic properties of reinforced solids: some theoretical principles. J. Mech. Phys. Solids 11(5), 357-372 (1963)

37. Kanit, T., Forest, S., Galliet, I., Mounoury, V., Jeulin, D.: Determination of the size of the representative volume element for random composites: statistical and numerical approach. Int. J. Solids Struct. 40(13-14), 3647-3679 (2003)

38. Tasan, C., Hoefnagels, J., Diehl, M., Yan, D., Roters, F., Raabe, D.: Strain localization and damage in dual phase steels investigated by coupled in-situ deformation experiments and crystal plasticity simulations. Int. J. Plast. 63, 198-210 (deformation Tensors in Material Modeling in Honor of Prof. Otto T, Bruhns) (2014)

39. Kadkhodapour, J., Butz, A., Ziaei-Rad, S., Schmauder, S.: A micro mechanical study on failure initiation of dual phase steels under tension using single crystal plasticity model. Int. J. Plast. 27(7), 1103-1125 (2011)

40. Paul, S.K.: Real microstructure based micromechanical model to simulate microstructural level deformation behavior and failure initiation in dp 590 steel. Mater. Des. 44, 397-406 (2013)

41. Tasan, C.C., Diehl, M., Yan, D., Zambaldi, C., Shanthraj, P., Roters, F., Raabe, D.: Integrated experimental-simulation analysis of stress and strain partitioning in multiphase alloys. Acta Mater. 81, 386-400 (2014)

42. Ramazani, A., Mukherjee, K., Quade, H., Prahl, U., Bleck, W.: Correlation between $2 \mathrm{~d}$ and $3 \mathrm{~d}$ flow curve modelling of dp steels using a microstructure-based rve approach. Mater. Sci. Eng. A 560, 129-139 (2013)

43. Zeghadi, A., N'guyen, F., Forest, S., Gourgues, A.F., Bouaziz, O.: Ensemble averaging stress-strain fields in polycrystalline aggregates with a constrained surface microstructure - part 1: anisotropic elastic behaviour. Philos. Mag. 87(8-9), 1401-1424 (2007)

44. Karlsson, B., Linden, G.: Plastic deformation of eutectoid steel with different cementite motphologies. Mater. Sci. Eng. 17, 153-164 (1975)

45. Karlsson, B., Linden, G.: Plastic deformation of ferrite-pearlite structures in steel. Mater. Sci. Eng. 17(2), 209-219 (1975)

46. Karlsson, B., Sundström, B.: Inhomogeneity in plastic deformation of two-phase steels. Mater. Sci. Eng. 16(1), 161-168 (1974)

47. Fritzen, F., Böhlke, T., Schnack, E.: Periodic three-dimensional mesh generation for crystalline aggregates based on Voronoi tessellations. Comput. Mech. 43(5), 701-713 (2008)

48. Johnson, W., Mehl, R.: Reaction kinetics in processes of nucleation and growth. Trans. Metall. Soc. AIME 135, 416-442 (1939)

49. Katani, S., Ziaei-Rad, S., Nouri, N., Saeidi, N., Kadkhodapour, J., Torabian, N., Schmauder, S.: Microstructure modelling of dual-phase steel using SEM micrographs and Voronoi polycrystal models. Metallogr. Microstruct. Anal. 2(3), 156-169 (2013) 
50. Regener, B., Krempaszky, C., Werner, E., Stockinger, M.: Modelling the micromorphology of heat treated ti6al4v forgings by means of spatial tessellations feasible for fem analyses of microscale residual stresses. Computational Materials Science 52(1), 77-81 (2012), proceedings of the 20th International Workshop on Computational Mechanics of Materials-IWCMM 20

51. Voronoi, G.: Nouvelles applications des paramètres continus à la théorie des formes quadratiques. premier mémoire. sur quelques propriétés des formes quadratiques positives parfaites. Journal für die reine und angewandte Mathematik 133, pp. 97-102 (1908)

52. Werner, E., Wesenjak, R., Fillafer, A., Meier, F., Krempaszky, C.: Microstructure-based modelling of multiphase materials and complex structures. Continuum Mech. Thermodyn. 28(5), 1325-1346 (2016)

53. Carolan, D., Chong, H., Ivankovic, A., Kinloch, A., Taylor, A.: Co-continuous polymer systems: a numerical investigation. Comput. Mater. Sci. 98, 24-33 (2015)

54. Sun, X.Y., Xu, G.K., Li, X., Feng, X.Q., Gao, H.: Mechanical properties and scaling laws of nanoporous gold. J. Appl. Phys. 113(2), $023505(2013)$

55. Zhang, J., Zhou, C., Wang, Y., Ju, L., Du, Q., Chi, X., Xu, D., Chen, D., Liu, Y., Liu, Z.: Extreme-scale phase field simulations of coarsening dynamics on the sunway taihulight supercomputer. In: Proceedings of the International Conference for High Performance Computing, Networking, Storage and Analysis, SC '16, pp. 4:1-4:12. IEEE Press, Piscataway, NJ, USA (2016)

56. Balzani, D., Scheunemann, L., Brands, D., Schröder, J.: Construction of two- and three-dimensional statistically similar rves for coupled micro-macro simulations. Comput. Mech. 54(5), 1269-1284 (2014)

57. Scheunemann, L., Schröder, J., Balzani, D., Brands, D.: Construction of statistically similar representative volume elementscomparative study regarding different statistical descriptors. Proc. Eng. 81, 1360-1365, : 11th International Conference on Technology of Plasticity, ICTP 2014, 19-24 October 2014. Nagoya Congress Center, Nagoya, Japan (2014)

58. Schröder, J., Balzani, D., Brands, D.: Approximation of random microstructures by periodic statistically similar representative volume elements based on lineal-path functions. Arch. Appl. Mech. 81(7), 975-997 (2011)

59. Bargmann, S., Klusemann, B., Markmann, J., Schnabel, J.E., Schneider, K., Soyarslan, C., Wilmers, J.: Generation of 3d representative volume elements for heterogeneous materials: a review. Progress Mater. Sci. 96, 322-384 (2018)

60. Arndt, D., Bangerth, W., Davydov, D., Heister, T., Heltai, L., Kronbichler, M., Maier, M., Pelteret, J.P., Turcksin, B., Wells, D.: The deal.ii library, version 8.5. J. Numer. Math. 24, 135-141 (2016)

61. Bangerth, W., Hartmann, R., Kanschat, G.: Deal.II-a general purpose object oriented finite element library. ACM Trans. Math. Softw. 33(4), 24:1-24:27 (2007)

62. Britz, D., Hegetschweiler, A., Roberts, M., Mücklich, F.: Reproducible surface contrasting and orientation correlation of low-carbon steels by time-resolved beraha color etching. Mater. Perform. Charact. 5(5), 553-563 (2016)

63. Mücklich, F., Engstler, M., Britz, D., Barrirero, J., Rossi, P.: Why we need all dimensions to solve both very old and very new questions in materials at the micro-, nano-and atomic scales. Pract. Metallogr. 52(9), 507-524 (2015)

64. Ohser, J., Mücklich, F.: Statistical Analysis of Microstructures in Materials Science. Wiley, New York (2000)

65. Chen, Z., Scheffer, T., Seibert, H., Diebels, S.: Macroindentation of a soft polymer: identification of hyperelasticity and validation by uni/biaxial tensile tests. Mech. Mater. 64, 111-127 (2013)

66. Chen, Z.: Nanoindentation testing of soft polymers: Computation, experiments and parameters identification. Ph.D. thesis, Universität des Saarlandes, Saarbrücken (2013)

67. Tarantola, A.: Inverse problem theory and methods for model parameter estimation. Society for Industrial and Applied Mathematics (2005)

68. Kelley, C.: Iterative methods for optimization. Frontiers in applied mathematics. Society for Industrial and Applied Mathematics (1999)

69. Lagarias, J.C., Reeds, J.A., Wright, M.H., Wright, P.E.: Convergence properties of the Nelder-Mead simplex method in low dimensions. SIAM J. Optim. 9(1), 112-147 (1998)

70. Nelder, J.A., Mead, R.: A simplex method for function minimization. Comput. J. 7, 308-313 (1965)

71. Kreißig, R., Benedix, U.: Höhere technische Mechanik. Springer, Berlin (2013)

72. Rösler, J., Harders, H., Bäker, M.: Mechanisches Verhalten der Werkstoffe. Springer, Berlin (2003)

73. Slaughter, W.: The Linearized Theory of Elasticity. Birkhäuser, Boston (2002)

74. Simo, J.C., Hughes, T.J.: Computational Inelasticity, Interdisciplinary Applied Mathematics, vol. 7. Springer, Berlin (2000)

75. Scherff, F.: Modellierung der Gefüge-Eigenschafts-Korrelation bei Dualphasenstahl. Ph.D. thesis, Universität des Saarlandes, Saarbrücken (2019)

76. Goldschmidt, F.: Modellierung und Simulation von Klebeverbindungen mit gradierten mechanischen Eigenschaften. Ph.D. thesis, Universität des Saarlandes, Saarbrücken (2015)

77. Scherff, F., Goldschmidt, F., Scholl, S., Diebels, S.: High-resolution simulation of microstructures in dual-phase steel. PAMM 16(1), 391-392 (2016)

78. Bednarcyk, B.A., Aboudi, J., Arnold, S.M.: The equivalence of the radial return and Mendelson methods for integrating the classical plasticity equations. Comput. Mech. 41(5), 733-737 (2008)

79. Simo, J., Taylor, R.: Consistent tangent operators for rate-independent elastoplasticity. Comput. Methods Appl. Mech. Eng. 48(1), 101-118 (1985)

80. Wilkins, M.L.: Calculation of elastic-plastic flow. Tech. rep. California Univ Livermore Radiation Lab (1963)

81. Altenbach, J., Altenbach, H.: Einführung in die Kontinuums-Mechanik. Teubner, Wiesbaden (1994)

82. Haupt, P.: Continuum Mechanics and Theory of Materials, 2nd edn. Springer, Berlin (2001)

83. Holzapfel, G.A.: Nonlinear Solid Mechanics. Wiley, New York (1999)

84. Truesdell, C., Toupin, R.: The classical field theories. In: Flügge, S. (ed.) Principles of Classical Mechanics and Field Theory, pp. 226-793. Springer, Berlin (1960)

85. Bonet, J., Wood, R.D.: Nonlinear Continuum Mechanics for Finite Element Analysis. Cambridge University Press, Cambridge (1997)

86. Kröner, E.: Allgemeine kontinuumstheorie der versetzungen und eigenspannungen. Arch. Rat. Mech. Anal. 4(1), 273-334 (1959) 
87. Lee, E.H.: Elastic-plastic deformation at finite strains. J. Appl. Mech. 36(1), 1-6 (1969)

88. Groeber, M., Ghosh, S., Uchic, M.D., Dimiduk, D.M.: A framework for automated analysis and simulation of 3d polycrystalline microstructures. Part 1: statistical characterization. Acta Mater. 56(6), 1257-1273 (2008)

89. Groeber, M., Ghosh, S., Uchic, M.D., Dimiduk, D.M.: A framework for automated analysis and simulation of 3d polycrystalline microstructures. Part 2: synthetic structure generation. Acta Mater. 56(6), 1274-1287 (2008)

90. Groeber, M.A., Jackson, M.A.: Dream.3d: a digital representation environment for the analysis of microstructure in $3 \mathrm{~d}$. Integr. Mater. Manuf. Innov. 3(1), 5 (2014)

91. Oliver, W.C., Pharr, G.M.: An improved technique for determining hardness and elastic modulus using load and displacement sensing indentation experiments. J. Mater. Res. 7(6), 1564-1583 (1992)

92. Cheng, Y.T., Cheng, C.M.: Can stress-strain relationships be obtained from indentation curves using conical and pyramidal indenters? J. Mater. Res. 14(9), 3493-3496 (1999)

93. Clausner, A.: Bewertung von Verfahren zur Fließspannungsbestimmung in der Nanoindentation. Ph.D. thesis, Technische Universität Chemnitz (2013)

Publisher's Note Springer Nature remains neutral with regard to jurisdictional claims in published maps and institutional affiliations. 